\title{
Erratum
}

\section{Intrastrand Parity Rules of DNA Base Composition and Usage Biases of Synonymous Codons}

\section{Noboru Sueoka}

Department of Molecular, Cellular, and Developmental Biology,

University of Colorado, Boulder, CO 80309-0347, USA

J Mol Evol (1995) 40:318-325

Page 324, With corrections of errors, the diagram of Appendix I and some equations in Appendix II should appear as follows:

\section{Appendix I: A Logical Derivation of PRI}

Appendix 2: Equations for the Calculation of $A, T$, $G$, and $C$ at Equilibrium

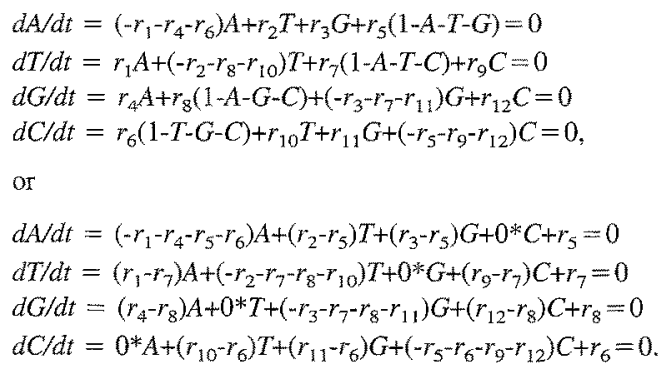

ISOTYPE SUBSTITUTIONS

\begin{tabular}{|c|c|}
\hline $\mathrm{A} \rightarrow \mathrm{T}\left(r_{1}\right)$ or $\mathrm{T} \rightarrow \mathrm{A}\left(r_{2}\right)$ & $\mathrm{G} \rightarrow \mathrm{C}\left(r_{11}\right)$ or $\mathrm{C} \rightarrow \mathrm{G}\left(r_{12}\right)$ \\
\hline $\begin{array}{ll}T, & A \\
\uparrow_{r}, & \uparrow_{r_{2}}\end{array}$ & $\begin{array}{ll}C & G \\
\uparrow_{r_{11}} & \uparrow_{r_{12}} \\
G & C,\end{array}$ \\
\hline $\begin{array}{ll}\downarrow_{\downarrow_{2}^{\prime}} & \downarrow_{\mathrm{A}}^{A} r_{1} \\
\end{array}$ & $\begin{array}{ll}\downarrow_{\downarrow_{12}^{\prime}}^{\mathrm{C}} & \stackrel{\mathrm{G}}{\downarrow^{\prime} r_{11}^{\prime}} \\
\mathrm{C}\end{array}$ \\
\hline $\begin{array}{l}\qquad r_{1}=r_{2} \quad r_{2}=r_{i} \quad \text { (BPA) } \\
\text { If no-strand-bias, } \\
\text { Therefore, } r_{1}=r_{1}:\end{array}$ & $\begin{array}{l}\qquad r_{11}=r_{12} \quad r_{12}=r_{11} \text { (BPA) } \\
\text { If no-strand-blas, } \\
\text { Therefore, }{ }^{\prime \prime}=r_{11} ;\end{array}$ \\
\hline $\begin{array}{l}r_{1}=r_{2} \\
r_{1}^{\prime}=r_{2}\end{array}$ & $\begin{array}{l}r_{19}=r_{12} \\
r_{11}=r_{12} .\end{array}$ \\
\hline
\end{tabular}

\section{ALLOYPE SUBSTITUTIONS}

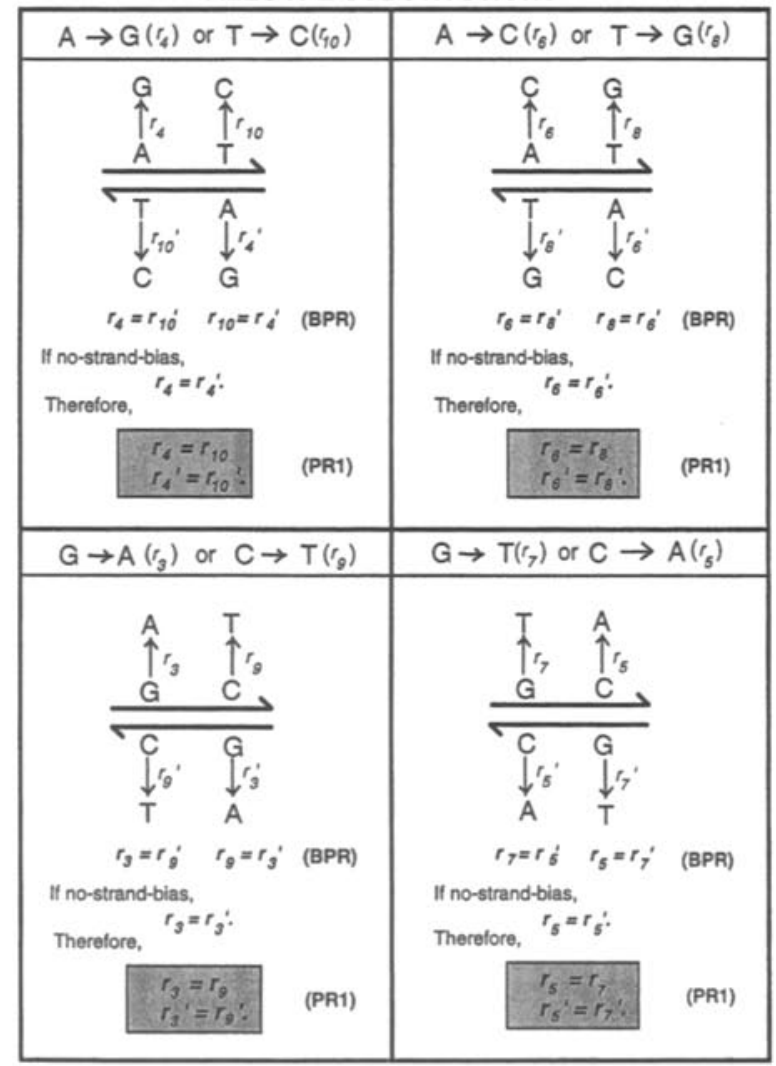

